\title{
Run to the nest: A parody on the Iron Maiden song by Corotoca spp. (Coleoptera, Staphylinidae)
}

\author{
Igor Eloi Moreira ${ }^{1,3}$; Carlos Moreno Pires-Silva ${ }^{1,4}$; Kézia Gomes Ribeiro ${ }^{1,5}$; Bruno Zilberman² \& Maria Avany Bezerra-Gusmão, \\ 1 Universidade Estadual da Paraíba (UEPB), Departamento de Biologia (DEPBIO), Laboratório de Ecologia de Térmitas. Campina Grande, PB, Brasil. \\ 2 Universidade de São Paulo (USP), Museu de Zoologia (MZUSP). São Paulo, SP, Brasil. \\ ORCID: http://orcid.org/0000-0003-2613-4827. E-mail: brunozilberman@usp.br \\ 3 ORCID: http://orcid.org/0000-0001-8013-8963. E-mail: eloi.igor@yandex.com \\ ${ }^{4}$ ORCID: http://orcid.org/0000-0002-6195-8648. E-mail: carlospsilvamoreno@gmail.com \\ ${ }^{5}$ ORCID: http://orcid.org/0000-0002-8490-6760. E-mail: keziaribeiro01@gmail.com \\ ${ }^{6}$ ORCID: http://orcid.org/0000-0002-1227-3167. E-mail: bezerra.gusma0@uepb.edu.br (corresponding author)
}

\begin{abstract}
Rove beetles belonging to the genus Corotoca (Staphylinidae: Aleocharinae) are termitophiles exclusively found in nests of Constrictotermes (Isoptera: Termitidae). We observed the reproductive behavior of Corotoca melantho and C. fontesi during host (Constrictotermes cyphergaster) foraging events. The reproductive behaviors of both species are similar. The variables collected for analysis were distance traveled, the time of larval deposition, nest return time, and locomotion speed. The fact that the female stops in the middle of the foraging trail to deposit the larva leads to a discussion of how its physiological or voluntary mechanisms function to determine the correct stopping time and the importance of speed when returning to the nest as a strategy to avoid predation. This study provides new information concerning the life cycle of Corotoca spp., although complete understanding of host-termitophile relationships, their evolutionary history, and the significance of viviparity will require additional studies.
\end{abstract}

Key-Words. Passive dispersal; Termite; Rove beetle; Termitophily.

\section{INTRODUCTION}

Active termite nests commonly house diverse species of rove beetles of the family Staphylinidae. The subfamily Aleocharinae is by far the most successful group of guests in termite nests (Seevers, 1957; Kistner, 1969; Cristaldo et al., 2012), and although those species are commonly found inside the nests, information concerning their ecology and behavior is still quite scarce (Kistner, 1969, Jacobson et al., 1986).

Termitophily has evolved several times among aleocharine rove beetles, and includes a wide range of morphologically specialized organisms. That habit emerged at least 99 mya, with fossil of extinct termitophilous Trichopseniini species known from mid-Cretaceous Burmese amber (Cai et al., 2017). Termitophylous clades have arisen at least 11 times in the subfamily Aleocharinae, with over 650 described species displaying a series of adaptations to either bribe or trick their hosts (Grassé, 1997; Kanao et al., 2016; Rosa et al., 2018). Two morphological adaptations have evolved: the inconspicuous horseshoe-shaped forebody form of the limuloid, and the large, conspicuous physogastric forms (Seevers, 1957). As discussed by Cristaldo et al. (2012), the limuloid body tends to minimize interactions with termite and maximize the hiding capabilities of the intruder species, while physogastric body forms maximize interactions with the termites and facilitate social integration. That view is corroborated by research on the origin of termitophily in Aleocharinae (Kanao et al., 2016) and their multiple interactions with their hosts (Grassé, 1997; Kistner, 1969).

Among the physogastric Aleocharinae, the pantropical tribe Corotocini contains the most specialized termitophilous organisms, and more than described 200 species. The tribe possibly evolved early within Nasutitermitinae, diversifying over a long period of time (rather than by frequent host transfers) (Jacobson et al., 1986). The genus Corotoca Schiødte 1853 comprises some of the most morphologically modified flightless and viviparous corotocine beetles with highly developed physogastic abdomens occurring since the first records of other animals living in association with termites (Schiødte, 1853). Those beetles are 
found only in association with the genus Constrictotermes Holmgren, 1910 (Isoptera: Termitidae) (Seevers, 1957), a genus found in evergreen and dry forests throughout South America (Cunha et al., 2006; Vasconcellos et al., 2010). It is not entirely clear how Corotoca species feed, although trophallaxis is probably involved (as evidenced by the reduction of the mouthparts in species of that genus) (Seevers, 1957; Zilberman, 2018b). The beetles also demonstrate general morphometric similarity to the host workers (Cunha et al., 2015), as has been reported for other termitophiles, and those inquilines also produce mimetic cuticular hydrocarbons (Rosa et al., 2018).

The larvae of the Corotoca females develop in their greatly enlarged abdomens (see Zilberman, 2018a: figs. 1, 2) and Seevers (1957) hypothesized that the larvae would pupate almost immediately after release as they "are released in an advanced stage". Seevers (I. c) also noted that no larvae had yet been found inside termite nests, and Oliveira et al. (2018) reported that adult females of the genus Corotoca visit termite foraging trails in order to deposit larvae.

Dispersing larval instars is uncommon among terrestrial invertebrates (Strathmann, 1990), and the process in which the animals are dispersed without energetic expense is called passive dispersal. That is the case with of dipterous species that are transported by birds (Green \& Sánchez, 2006), and gypsy moths that are transported by the wind (Mcmanus \& Mason, 1983). What makes Corotoca spp. dispersal so intriguing is the fact that the larvae are transported by workers along a foraging trail (Oliveira et al., 2018). Phoresy between adult Aleocharinae and termite hosts is not uncommon (Kistner, 1969), although the significance of that behavior to the inquiline species is still unclear and using foraging as a dispersal vehicle of phoretic behavior is even more intriguing.

We collected data on the reproductive behavior of Corotoca spp. (the distance traveled, time until stopping for depositing the larvae, and time required for returning to nest) in a semiarid region of Brazil in an attempt to discover how behavioral variables interact and shape that phenomenon.

\section{MATERIALS AND METHODS}

\section{Sample site}

Data were collected at the São João do Cariri Experimental Station (EESJC) (Fig. 1) in Paraíba State, Brazil. The station is managed by the Federal University of Paraíba, and is located in Cariri of Paraíba. The regional environment is dominated by dry forest and well-spaced shrubby Caatinga vegetation (Bucher, 1982); the climate
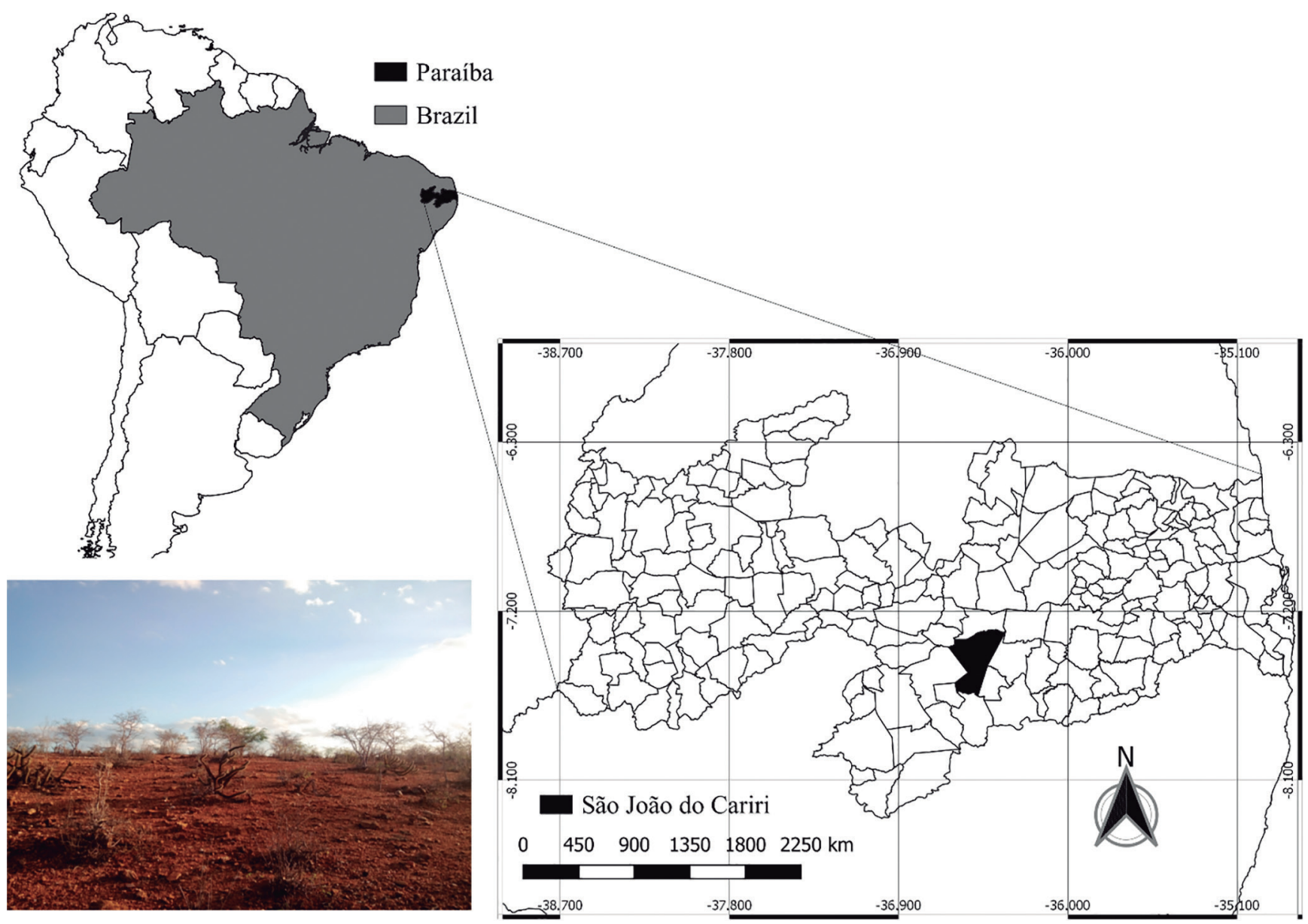

Figure 1. São João do Cariri Experimental Station (ESSJC). The station is located in a semiarid environment with some ongoing processes of desertification. Efforts are currently being made to aid the recovery of the local fauna and flora. 

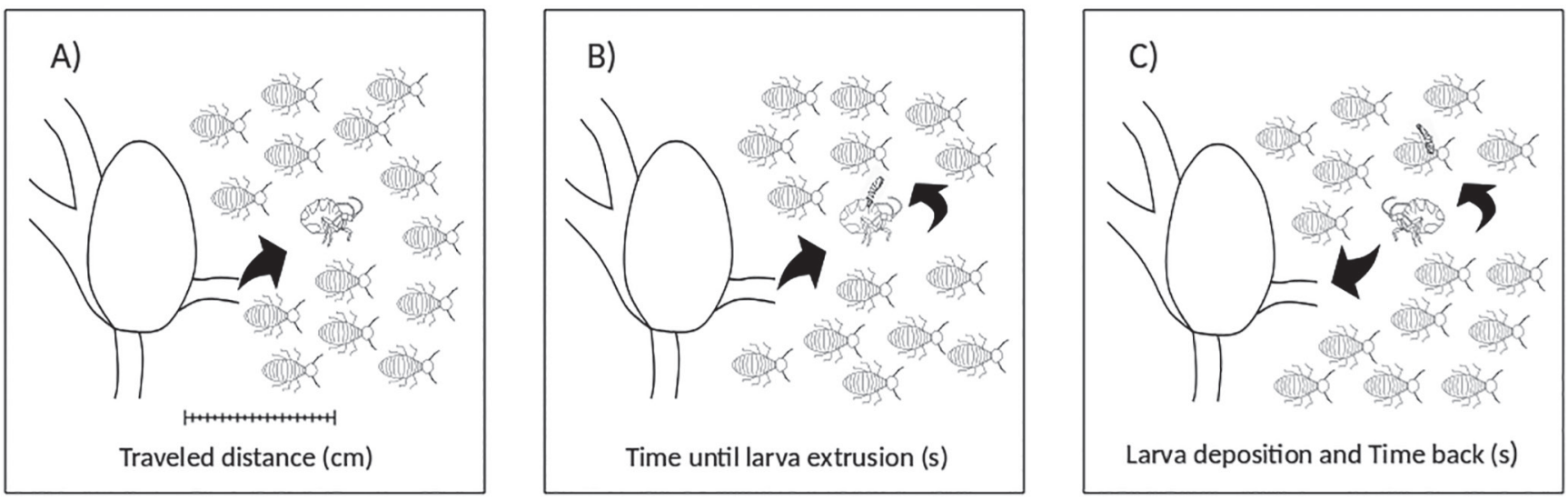

Figure 2. Scheme of the collection methodology: (A) Corotoca spp. leaves the nest to follow the host foraging trail. It is closely observed until stopping; the distance from the nest to where the beetle stops is measured and the time required is recorded; (B) When the beetle stops, the stopwatch is paused while larval extrusion occurs; (C) After larval the position, the return time of the beetle to the nest is recorded.

is semiarid and hot, the rainfall rates there are the lowest in the Brazilian semiarid region, annual mean precipitation is below $400 \mathrm{~mm}$ (Cohen \& Duqué, 2001), and the mean annual temperature is $26^{\circ} \mathrm{C}$ (Barbosa et al., 2007).

\section{Data collection}

Field excursions were undertaken in November/2017 and in January/2018. The foraging trails of five nests of Constrictotermes cyphergaster were monitored and data on the reproductive behavior of Corotoca spp. $(n=24)$ was collected (12 specimens of each species), noting the time when foraging initiated and when each beetle left the nest. We measured the distances traveled (using a tape measure, in $\mathrm{cm}$ ), the time until larval extrusion, and the time required for returning to the nest (using a stopwatch) - with pauses during the process of larval deposition (Oliveira et al., 2018) (Fig. 2). The beetles were collected using a thin forceps as soon as they returned to the entrance of the nest. Collecting beetles from the trails naturally caused disturbances of its flow, so that intervals of at least five minutes were respected after each collection before restarting monitoring. The egression speed of the beetles was calculated by dividing the time until stopping by the distance traveled (V1); the regression speed was calculated by noting the time required to return to the nest (V2).

The collected specimens were identified (Corotoca melantho and C. fontesi) using the key provided in Zilberman (2018b). Voucher specimens were deposited in the Termite Ecology Laboratory at the State University of Paraíba.

\section{Data analysis}

We tested the normality of data collected using visual analyses of density and the Shapiro-Wilk test. Some of the variables failed to satisfy the requirements of normality (Time until stopping $(P<0.01)$ and V1 $(P<0.001)$ ). We tested the homogeneity of the errors of the normal variables using Bartlett's test (all $P>0.05$ ). The Student's $T$ tests was performed using species as factors $(x$-var) in order to determine if there were differences between the species.

The speeds of the beetles were compared (V1 against V2) using the Mann-Whitney test, and the differences between species for both V1 and V2 were compared using the Mann-Whitney and Student's $t$ test respectively.

A multiple linear model was then constructed using the time required to return as the response $(y$-var) and distance plus time until stopping as the explanatory variable $(x$-var). Separate regression analyses for both predictors were conducted.

The times of day when the beetles left the nest where analyzed in order to discover possible patterns and peaks in Corotoca spp. trail visiting frequencies (leaving nest $\sim$ time) by building a contingency table and using the $x^{2}$ test. Correlation analysis among variables was conducted using Spearman's rank. All of the analyses were conducted using R version 3.2.3 software (R Core Team, 2015).

\section{RESULTS}

Both species (Corotoca melantho and C. fontesi) display very similar reproductive behaviors in terms of larval extrusion (Table 1). The multiple linear models using Distance + Time until stopping as explanatory variables showed that both variables were significantly related to

Table 1. Descriptives of the sampled variables for each species during larvae extrusion, deposition, and returning to the nest of Corotoca melantho and C. fontesi along the foraging trails of its host $(\mathrm{N}=24)$.

\begin{tabular}{|c|c|c|c|c|c|c|}
\hline \multirow{2}{*}{ Descriptive } & \multirow{2}{*}{ Species } & \multirow{2}{*}{$\begin{array}{l}\text { Distance } \\
\text { traveled }\end{array}$} & \multicolumn{2}{|c|}{ Time (seconds) until } & \multirow{2}{*}{ V1 } & \multirow{2}{*}{ V2 } \\
\hline & & & Stopping & Returning & & \\
\hline \multirow[t]{2}{*}{ Mean } & C. fontesi & 24.0 & 30.5 & 64.0 & 1.48 & 4.06 \\
\hline & C. melantho & 19.3 & 34.4 & 61.6 & 2.73 & 5.18 \\
\hline \multirow[t]{2}{*}{ Median } & C. fontesi & 24.5 & 31.5 & 68.5 & 1.26 & 3.19 \\
\hline & C. melantho & 17.5 & 22.0 & 61.0 & 1.43 & 3.18 \\
\hline \multirow[t]{2}{*}{ SD } & C. fontesi & 14.4 & 16.6 & 26.9 & 0.878 & 2.98 \\
\hline & C. melantho & 12.0 & 29.4 & 36.0 & 3.43 & 5.26 \\
\hline
\end{tabular}




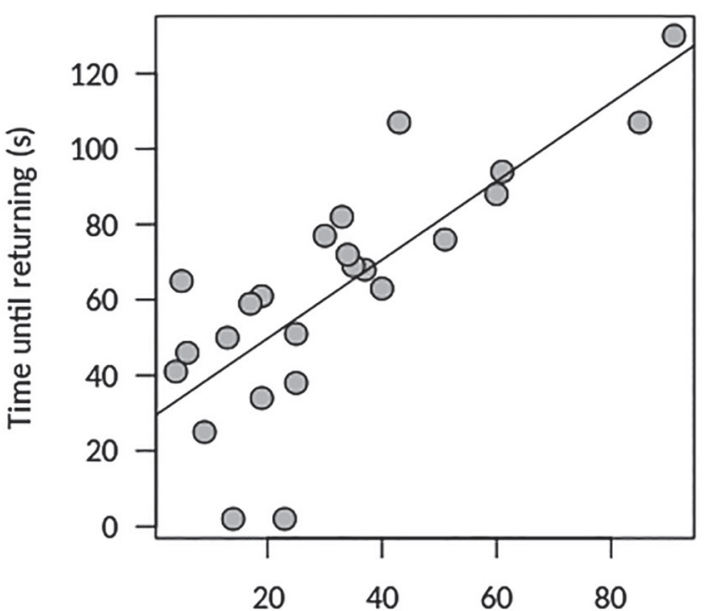

Time until stopping (s)

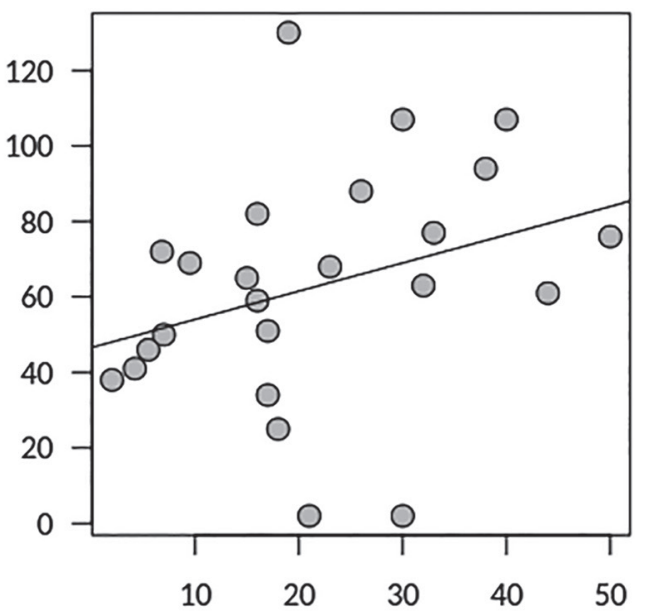

Distance $(\mathrm{cm})$

Figure 3. Simple regressions using each of the independent variables of the multiple linear regressions for time until extrusion and return to the nest by Corotoca melantho and C. fontesi. Left: return time ( $y$-var) vs time until stopping $\left(x\right.$-var) $\left(R^{2}=0.6152 ; F=35.17, P<0.001\right)$; Right: return time vs distance traveled ( $x$-var) $\left(R^{2}=0.10 ; F=6.461, P=0.13\right)$.
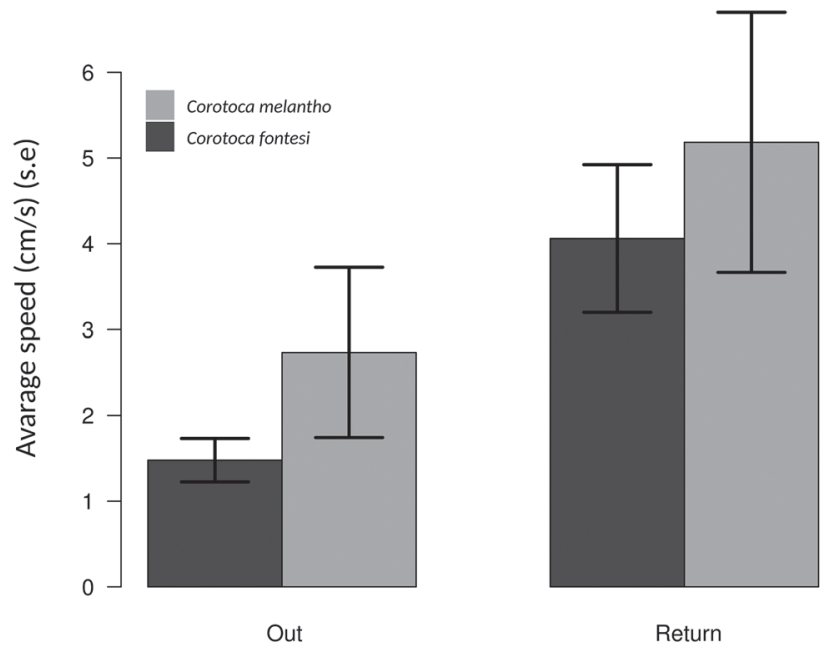

Figure 4. Bar plots of the average speeds of the two beetle species (bars represent the standard errors of the means). Lighter bars represent $\mathrm{V} 1$ (the out of nest velocity) while the darker bars represent V2 (the return speed). Higher speed spindle as are observed when returning to the nest.

the time until returning $\left(R^{2}=0.6203 ; P<0.001\right)$. The time until stopping $\left(\mathrm{F}_{1,21}=28.7478 ; \mathrm{P}<0.001\right)$ and distance traveled $\left(F_{1,21}=5.5645, P<0.05\right)$ both significantly influenced the response (return) (Fig. 3).

Surprisingly, the coefficient of Time to stopping (1.094) displayed a positive influence on the return time (31.477) while distance exhibited a negative effect $(-0.193)$. That situation can be explained by the higher return speed (Fig. 4).

We observed statistical differences between the dislocation speeds of the beetles and the direction that they were moving (both species) $(U=137 ; P<0.01)$ (Fig. 3$)$, with returning to the nest speeds (V2) being higher than those of leaving the nest (V1). There were no differences between the two species regarding $\mathrm{V} 1(\mathrm{U}=62 ; \mathrm{P}>0.05)$ and V2 ( $T=-0.64307$, d.f $=22, P>0.05$ ) (Table 2), as both displayed a higher $\mathrm{V} 2$. We recorded 12 individuals of each species during the observations. The most beetles
Table 2. Pair-wise comparisons (by species) of the collected variables show no differences between Corotoca melantho and C. fontesi regarding larval deposition. A non-parametric test was used for non-normal variables (Time until stopping).

\begin{tabular}{llccc}
\hline \multicolumn{1}{c}{ Variable } & \multicolumn{1}{c}{ Test } & Statistic & d.f & p \\
\hline Distance $(\mathrm{cm})$ & Student'T & 0.867 & 22 & 0.395 \\
Time until stopping(s) & Mann-Whitney's U & 68 & - & 0.583 \\
Return time(s) & Student's $T$ & 0.186 & 22 & 0.854 \\
\hline
\end{tabular}

left the nest between $23 \mathrm{~h}$ and $01 \mathrm{~h} \mathrm{~h}(91.7,66 \%)$. No significant statistical differences were observed in terms of the numbers of individuals leaving the nests at any sampling time $\left(X^{2}=12, d . f=9, P>0.05\right)$.

\section{DISCUSSION}

We collected data on two species of viviparous Aleocharinae that live in exclusive relationships with their host. Corotoca melantho and C. fontesi displayed very similar behaviors of passive dispersal of their larvae, which raises the possibility that viviparity (as a character) and the behavior of dispersing immatures might represent a trait that evolved previous to the separation of Corotoca + Spirachta (sister groups), given that the latter species had also been observed accompanying the foraging parties of its host (Constrictotermes cavifrons Holmgren, 1910) (Kistner, 1969). Unfortunately, the viviparity of Spirachta is still to be confirmed (Zilberman et al., in prep).

We found that the distance traveled is not the main factor causing increased return time, but rather a higher average return speed (Fig. 4). Such behavior can be interpreted as a strategy to avoid predation, since termites are often attacked by natural enemies while foraging (Eisenmann, 1961; Sheppe, 1970).

Because the female is never found outside the nest without carrying at least a second larva, she not only risks 
her own life, but the life of a future generation of individuals carrying her genes. The foraging trails of $C$. cyphergaster are guarded along their edges by a line of aggressive and quickly triggered soldiers, while workers move quickly in a single direction in the center (Moura et al., 2006) and the beetles are never seen along the margins of the termite trails (Oliveira et al., 2018). As pointed out by Hamilton (1971), when moving in groups, animals in the middle are safer than those along the edges. Therefore, walking among workers, and between lines of altruistic soldiers willing to sacrifice their own lives, can be interpreted as a strategy to increase the beetle's fitness. Traveling longer distances still presents a higher risk to the beetles (Magnhagen, 1991), however, although the farther away a mother leaves her brood, the less chance there is that the larva will return to the nest as a stenogastric adult. We are still testing this hypothesis, but literature on the evolution of flightless beetles points to the fact that returning to the place of origin (nest) tends to diminish the genetic variability of the species and leads to greater genetic distances (Ikeda et al., 2012).

Regarding the fact that Corotoca spp. must stop in the middle of the foraging trail to deposit its larva, two principal hypotheses have been put forward: i) stopping is motivated by the physiological needs of the female rather than by any voluntary mechanism. Thus, the female would move forward on the trail until the moment of larval extrusion. This theory is actually corroborated by the positive correlation between those variables $(\mathrm{S}=1189.6, \mathrm{P}<0.05)$; ii) the second hypothesis predicts that the mechanism of larval extrusion is fully (or largely) controlled by the female, and that the insect will walk in safety for as long as possible before extrusion. Therefore, as the larva reaches maturity within the maternal body, successful extrusion can occur wherever the mother beetle is. This theory is corroborated by the fact that when disturbed (in the laboratory), the females will usually expel a larva in a late stage of development, possibly as a strategy to save that offspring (as the larvae are much

Corotoca melantho more rapid and display more mobility than the adults) (Zilberman et al., in prep). Both theories might be wrong, or a combination of both might better fit the natural history of the genus.

Upon stopping, the female will recruit a worker to carry the larva (Oliveira et al., 2018). This does not happen immediately, however, and the beetles may employ some cue that signals "stop" to the termites, in a manner similar to that reported by Hölldobler (1971) and Quinet \& Pasteels (1995) for myrmecophilous Aleocharinae. The existence of chemical signals is well recognized in the literature, and is extremely important to the organization of social insects (Czaczkes et al., 2015). As termites respond to the intensity of such cues, not all of the workers passing by the beetle would be expected to stop (given the marking by scout soldiers of cues that signal "follow the trail") as the "stop" signal of the female could be very faint.

As shown in Fig. 3 (Right), distance is not statistically influential in the return time response $(P>0.05)$ and is only weakly correlated to it $\left(R^{2}=0.10\right)$ because individuals return much faster once larval extrusion occurs. The average speed of the returning beetles may increase because of the loss of the larval mass. When a nest was observed to have fallen from its support tree on one occasion, we observed Corotoca beetles following the termites into ground borrows (where a new nest would be constructed) at considerable speeds, which indicates that the beetles can move rapidly when necessary.

Our collection chart indicates that the beetles will come out of the nest within the short time span (three hours) of active foraging (Fig. 5). The beetles leave the nest solely to disperse their larvae, and that movement is completely dependent on the occurrence of foraging events; no beetles leave the nest before 23:00. The foraging of $C$. cyphergaster in the EESJC in the northeastern Caatinga region was observed to begin near 22:00 (Moura et al., 2006), but requires up to one hour to establish an intense flow (no data is available, however, for other sites). Given that environmental factors are oth-

Corotoca fontesi

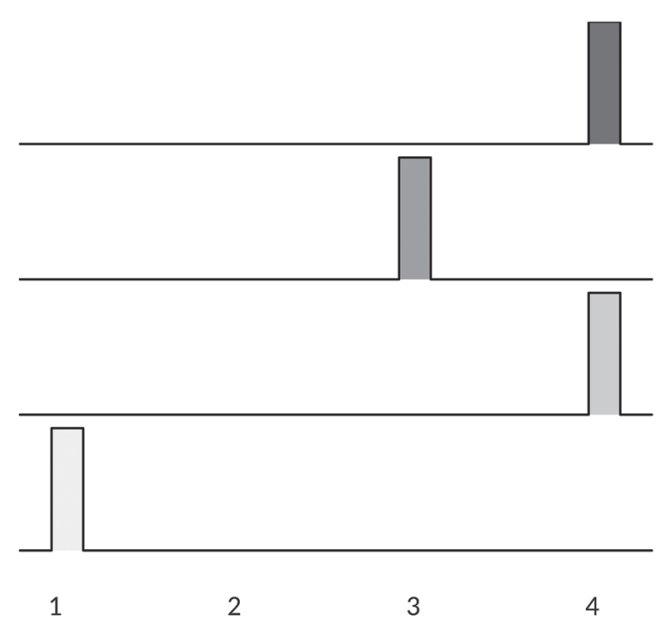

Number of beetles that left the nest per hour

Figure 5. This model-chart represents the numbers of individuals leaving the nests each hour, by species (individuals leaving the nests during the 60 minutes that compose a given hour are grouped within the same hour). 
erwise constant in the Caatinga domain, the trigger for Corotoca spp. exiting the nest is probably the intensity of termites in the foraging trail.

C. cyphergaster foraging occurs in "herds", but not all workers leave the nest simultaneously. Workers that have filled their crops will gradually return to the nest, and more workers will soon leave to feed (Bezerra-Gusmão, pers. obs.). This increased movement in the nest (between 22:00 and 23:00) can be interpreted by the beetle as a signal that foraging is occurring (although it will naturally decrease over time). As time passes, more workers tend to return to nest than leave it, which means that the chances of any worker carrying the larva upstream will decrease. The time at which this turnover of events occurs is approximately 02:00 (Moura et al., 2006), which agrees in detail with our sampling data (Fig. 5).

This paper is the second to describe the reproductive behavior of termitophile from field observations (following Oliveira et al., 2018), and reveals important points regarding termitophily and the life-cycle of viviparous Aleocharinae.

\section{ACKNOWLEDGMENTS}

The authors thank Mr. Gilberto Lima from ESSJC for his warm hospitality during our field collections. IEM was funded by a Conselho Nacional de Pesquisa-CNPq/ Programa de Iniciação Científica-PIBIC scholarship. Roy Funch is thanked for reviewing the English.

\section{REFERENCES}

Barbosa, M.; De Lima, I.; Roberto Lima, J.; Pessoa Cunha, J.; Agra, M. \& Thomas, W. 2007. Vegetação e Flora no Cariri Paraibano. Oecologia Brasiliensis, 11:313-322. D0I

Bucher, E.H. 1982. Chaco and Caatinga - South American Arid Savannas, Woodlands and Thickets. In: Huntley, B.J. \& Walker, B.H. (Eds.). Ecology of Tropical Savannas, Ecological Studies. Berlin, Springer p. 48-79. (Ecological Studies, n. 42),

Cai, C.; Huang, D.; Newton, A.F.; Eldredge, K.T. \& Engel, M.S. 2017. Early evolution of specialized termitophily in Cretaceous Rove Beetles. Current Biology, 27: 1229-1235. DOI

Cohen, M. \& Duqué, G. 2001. Les deux visages du Sertão: stratégies paysannes face aux sécheresses (Nordeste du Brésil). Paris, IRD Editions. 390p.

Cristaldo, P.F.; Rosa, C.S.; Florencio, D.F.; Marins, A. \& DeSouza, 0. 2012. Termitarium volume as a determinant of invasion by obligatory termitophiles and inquilines in the nests of Constrictotermes cyphergaster (Termitidae, Nasutitermitinae). Insectes Sociaux, 59: 541-548.

Cunha, H.F. da; Lima, J.S.; Souza, L.F. de; Santos, L.G.A. dos \& Nabout, J.C. 2015. No Morphometric distinction between the host Constrictotermes cyphergaster (Silvestri) (Isoptera: Termitidae, Nasutitermitinae) and its obligatory Termitophile Corotoca melantho Schiødte (Coleoptera: Staphylinidae). Sociobiology, 62(1): 65-69.

Cunha, H.F.; Costa, D.A.\& Brandão, D. 2006. Termite (Isoptera) assemblages in some regions of the Goiás State, Brazil. Sociobiology, 47: 505-517.

Czaczkes, T.J.; Grüter, C. \& Ratnieks, F.L.W. 2015. Trail Pheromones: An Integrative View of Their Role in Social Insect Colony Organization. Annual Review of Entomology, 60: 581-599.
Eisenmann, E. 1961. Favorite Foods of Neotropical Birds: Flying Termites and Cecropia Catkins. The Auk, 78: 636-638. DOI

Grassé, P.-P. 1997. Termitologia Tome 3: Comportement, socialité, écologie, évolution, systématique. Paris, Elsevier Masson.

Green, A.J. \& Sánchez, M.I. 2006. Passive internal dispersal of insect larvae by migratory birds. Biology Letters, 2: 55-57. D01

Hamilton, W.D. 1971. Geometry for the selfish herd. Journal Theoretical Biology, 31: 295-311.

Hölldobler, B. 1971. Communication between Ants and Their Guests. Scientific American, 224: 86-93. DOI

Ikeda, H.; Nishikawa, M. \& Sota, T. 2012. Loss of flight promotes beetle diversification. Nature Communications, 3: 648. DOI

Jacobson, H.; Kistner, D. \& Pasteels, J.M. 1986. Generic Revision, Phylogenetic Classification, and Phylogeny of the Termiophilous Tribe Corotocini (Coleoptera: Staphylinidae). Sociobiology, 12: 1-239.

Kanao, T.; Eldredge, K. \& Maruyama, M. 2016. A defensive body plan was pre-adaptive for termitophily in the rove beetle tribe Termitohospitini (Staphylinidae: Aleocharinae). BioRxiv, 083881. DOI

Kistner, D.H. 1969. The Biology of Termitophiles. In: Krishna, K. \& Weesner, F.M. The Biology of Termites. New York, Academic Press. p. 525-557.

Magnhagen, C. 1991. Predation risk as a cost of reproduction. Trends in Ecology \& Evolution, 6: 183-186. DOI

Mcmanus, M.L. \& Mason, C.J. 1983. Determination of the Settling Velocity and Its Significance to Larval Dispersal of the Gypsy Moth (Lepidoptera: Lymantriidae). Environmental Entomology, 12: 270-272. D0I

Moura, F.M.S.; Vasconcellos, A.; Araújo, V.F.P. \& Bandeira, A.G. 2006. Seasonality in foraging behaviour of Constrictotermes cyphergaster (Termitidae, Nasutitermitinae) in the Caatinga of Northeastern Brazil. Insectes Sociaux, 53: 472-479. DOI

Oliveira, M.H. de; Vieira, R.V. da S.; Moreira, I.E.; Pires-Silva, C.M.; Lima, H.V.G. de; Andrade, M.R. de L. \& Bezerra-Gusmão, M.A. 2018. "The road to reproduction": foraging trails of Constrictotermes cyphergaster (Termitidae: Nasutitermitinae) as maternities for Staphylinidae beetles. Sociobiology, 65:531-533. DOI

Quinet, Y. \& Pasteels, J.M. 1995. Trail following and stowaway behaviour of the myrmecophilous staphylinid beetle, Homoeusa acuminata, during foraging trips of its host Lasius fuliginosus (Hymenoptera: Formicidae). Insectes Sociaux, 42: 31-44. D0I

Rosa, C.S.; Cristaldo, P.F.; Florencio, D.F.; Marins, A.; Lima, E.R. \& DeSouza, 0. 2018. On the chemical disguise of a physogastric Termitophilous Rove Beetle. Sociobiology, 65: 38-47. D01

Schiødte, J.M. 1853. On some Staphylinidae, found in the nests of termites. Proceedings of the Zoological Society of London, 21: 101-103.

Seevers, C.H. 1957. A Monograph on the Termitophilous Staphylinidae (Coleoptera). Fieldiana Zoology, 40: 1-334.

Sheppe, W. 1970. Invertebrate predation on termites of the African Savanna. Insectes Sociaux, 17: 205-218. DOI

Strathmann, R.R. 1990. Why Life Histories Evolve Differently in the Sea. Integrative and Comparative Biology, 30: 197-207. D0I

Vasconcellos, A.; Bandeira, A.G.; Moura, F.M.; Araujo, V.F.; Gusmao, M.A. \& Constantino, R. 2010. Termite assemblages in three habitats under different disturbance regimes in the semi-arid Caatinga of NE Brazil. Journal of Arid Environments, 74: 298-302.

Zilberman, B. 2018a. New species and synonymy in the genus Corotoca Schiødte, 1853 (Coleoptera, Aleocharinae, Corotocini). Zootaxa, 4434: 547-560. D0I

Zilberman, B. 2018b. Revisão taxonômica e análise cladística do gênero Corotoca Schiodte 1853 (Coleoptera, Staphylinidae, Aleocharinae, Corotocini) (Master Dissertation). Universidade de São Paulo, São Paulo. http://www.teses. usp.br/teses/disponiveis/38/38131/tde-04102018-163811/pt-br.php. 